\title{
MINDS: Toward a computerized test battery for use in health psychological and neuropsychological assessment
}

\author{
NICO BRAND \\ University of Utrecht, Utrecht, The Netherlands \\ and \\ PETER J. HOUX \\ University of Limburg, Maastricht, The Netherlands
}

\begin{abstract}
MINDS (Mental Information Processing and Neuropsychological Diagnostic System) was developed with the goal of integrating a number of independent and stand-alone test programs that are used in the diagnosis of psychological and neuropsychological health. The system runs under MS-DOS. The shell program integrates subject information with data obtained through the use of the individual test programs. The current test battery comprises tasks on memory, attention, and motor performance; these tasks require the use of additional peripheral response devices, which are controlled via a multiple I/O interface card. Questionnaires are also included; they have been developed with the author language shell program MicroCAT. MINDS is programmed to allow easy integration of new tests. As an example, the Motor Planning Test is described. The equivalence of the computerized questionnaires with existing tests is also discussed.
\end{abstract}

The advantages of computerized psychological testing in clinical practice are increasingly being acknowledged (West, Christie, \& Weinman, 1990). These advantages include the increased standardization of test administration and instructions, the immediate availability of errorfree test outcomes and scores, the power of adaptive tests (Weiss \& Vale, 1987) or conditional branching, and the capability of assessing more than one dependent variable at the same time, such as reaction times and psychophysiological measures.

The decreasing costs and increasing power of microcomputers have also increased the feasibility of computerized testing in clinical practice. However, many clinicians do not have much knowledge of hardware and software. They need computerized tests with minimal demands on knowledge of operating system commands or keyboard handling.

Many performance tests and questionnaires have been automated, but these tests lack standardization in several respects. These include screen layout, the assignment of keys for certain options (e.g., interruption of the test, review of previous items, etc.), the organization of data, and so on.

Peter J. Houx is in the Department of Neuropsychology and Psychobiology at the University of Limburg. Correspondence concerning this article should be addressed to Nico Brand, Department of Clinical and Health Psychology, University of Utrecht, Heidelberglaan 1, 3584 CS Utrecht, The Netherlands.

\section{MINDS: Toward an Easy-to-Use \\ Computerized Test Battery}

The MINDS system (Mental Information Processing and Neuropsychological Diagnostic System) was developed with the goal of integrating a number of independent test programs used in the diagnosis of psychological and neuropsychological health and research. Its development is based in part on earlier work with an Apple II (Brand \& Jolles, 1988). The test battery comprises both cognitive performance tests and health-related questionnaires.

The heart of the system is the shell program MINDSHLL, which integrates subject information with the data resulting from the use of the individual test programs. Within this shell program, executable files and batch files can be run. Performance tests (tests on memory, motor aspects, and attention), questionnaires, and programs that process the resulting data are included in the shell. These three types of programs can be started from different submenus; other submenus contain options for starting additional programs and DOS commands.

\section{Performance Tests}

The shell program incorporates the following performance tests.

Visual Fifteen-Word Learning Test (Brand \& Jolles, 1985; Brand, Jolles, \& Gispen-de Wied, in press). This test, which is adapted from Rey's Auditory Verbal Learning Test, measures aspects of short- and long-term verbal memory. 
Memory Comparison Test (Brand \& Jolles, 1987). This test, based on Sternberg's (1975) work, allows the decomposition of reaction time into discrete informationprocessing stages, as far as short-term memory is concerned.

Motor-Planning Test (Brand, Wijk, \& Hijman, 1990). In this choice reaction time test, simple finger movements are required, and both preparatory (motor-planning) states and the movement itself are timed and quantified.

Finger-Tapping Test (Brand \& Jolles, 1988). This test measures basic speed in relation to lateralized motor functioning, and it can also be used to assess sustained processing and time-on-task effects (Houx, 1991).

Vigilance Test. This test for visual sustained attention is based on Wilkinson's (1970) acoustical attention test.

Threatening Words Test. In this task, threatening and neutral words are presented, and recognition is assessed in order to reveal the influence of perceptual defense on recognition memory.

Perceptual Defense Test (Brand, Olff, Hulsman, \& Slagman, 1991). In this task, which is based on work by Mattson and Natsoulas (1962), tachistoscopically presented digitized photographs are used to assess both perceptual defense and vigilance.

Most of these tests make use of separate response devices which are interfaced to a commercially available multiple I/O card (Type 8255). The software routines are organized in separate units. With these units, reaction time can be measured from the response devices with millisecond accuracy (Hamers, Houx, Brand, \& Jolles, 1992).
On some tests (Fifteen-Word Test; Memory Comparison Test; Threatening Words Test), thumb-keys are pressed for binary yes/no responses; graphic stimuli are used in these tests. On other tests (Motor Planning Test; Tapping Test; Vigilance Test), a small box contains six buttons (LEDs) that can be lit. One task (Perceptual Defense Test) makes use of additional hardware-namely, the 16-bit TARGA board from AT\&T (Truevision Advanced Raster Graphics Adaptor) and a second (multisync) monitor.

In each of these tests, a number of test parameters can be changed (e.g., stimulus duration, stimulus sets, the order of presentation, etc.). As an example, the parameter screen of the Motor Planning Test is presented in Figure 1. Each test parameter has a default value that can be changed if one desires. Test runs may be interrupted at any time, although provisions have not been made for all tests to save the data at the point of interruption.

The first five tests were also part of the earlier Apple II test battery (Brand \& Jolles, 1988). A large amount of data have been collected with that system, particularly from psychiatric and neurological patients (Brand, 1987; Brand et al., in press; Brand et al., 1990). In addition, normative data have been gathered in normal healthy subjects with ages ranging from 20 to 80 years (Houx, 1991).

\section{Questionnaires}

At present, the following health-related and other questionnaires are included.

Utrecht Coping List (Schreurs, Willege, Tellegen, \& Brosschot, 1988). This test quantifies the ways in which

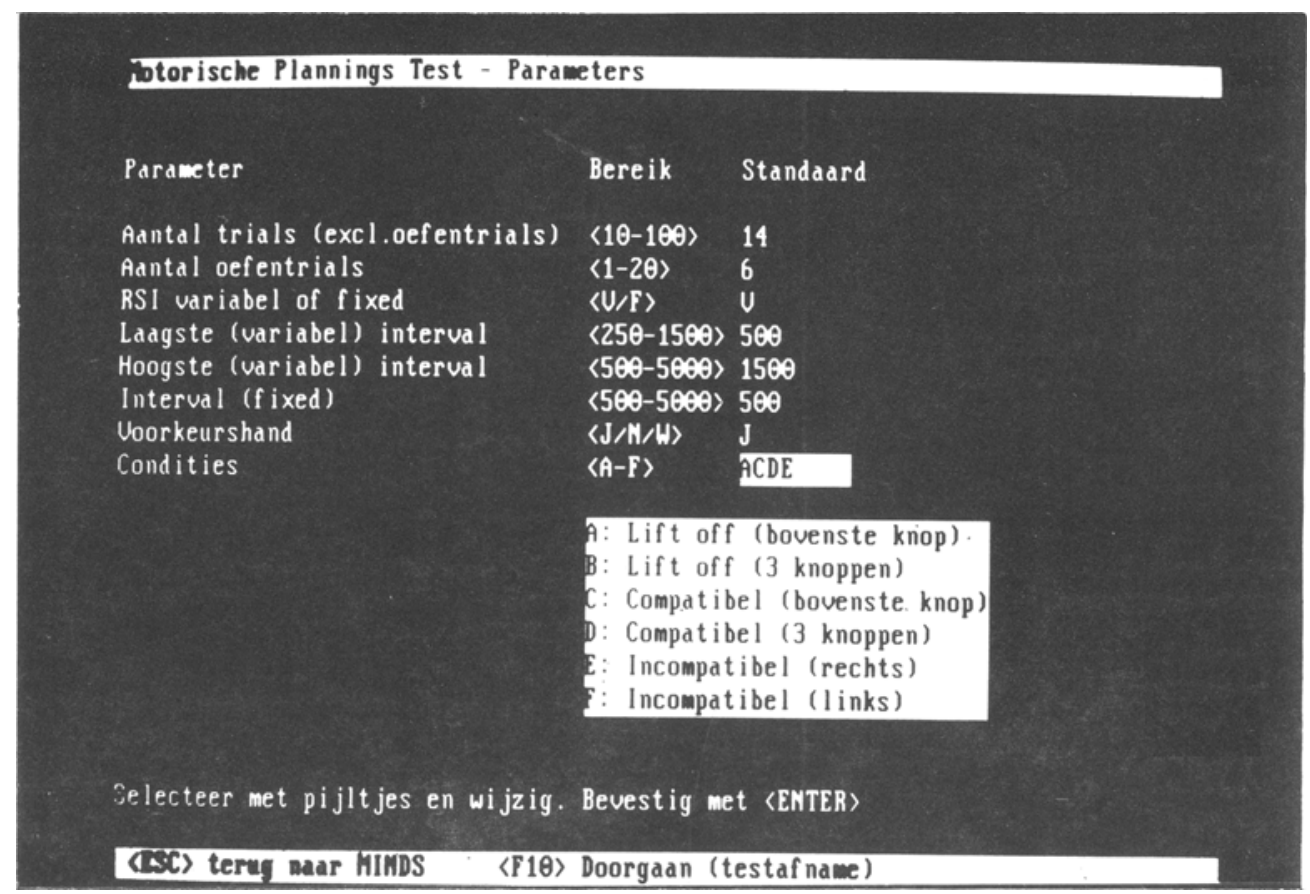

Figure 1. Parameter screen of the Motor Planning Test. 
people generally cope with problems; it consists of 47 items that cover seven ways of coping.

State and Trait Anxiety Test (Ploeg, 1982). Forty items measure state and trait anxiety.

Symptom Check List (Derogatis, Lipman, \& Covi, 1973). This test consists of 90 items that measure nine domains of psychological and psychosomatic complaints.

Computer Attitude Scale (Bouman, Wolters, \& WoltersHoff, 1989). Sixteen items measure positive or negative attitudes toward computers.

Daily Stressors Check List (Vingerhoets, Jeninga, \& Menges, 1989). This test consists of 114 daily "hassles." The scoring results in the frequency with which these "hassles" are encountered, as well as their mean intensity. A total score (frequency $X$ intensity) is also calculated.

These questionnaires are based on existing paper-andpencil instruments. They have been developed with the program MicroCAT (Brand \& Mol, 1989; Weiss \& Vale, 1987), which can be used to create both adaptive tests and conventional, fixed-length questionnaires. It is easy to develop questionnaires with this software; college students can do it without much help. Test items are created in monochrome text or in color graphics, which can be united into complete test specifications, compiled, and administered.

Tests constructed with this system may consist of items with up to six forced-choice alternatives. By using commands from its authoring language (MCATL: Minnesota Computerized Adaptive Testing Language), one can incorporate various options (e.g., reviewing previous items, measuring response times to individual items, conditional branching, etc.). However, MCATL is not easy to use. Other limitations are the primitive user interface and the fact that MicroCAT does not have a ready-made facility for presenting reports based on individual data-reports that might be of use in diagnostic practice. Thus, although the administration applications were implemented in the MINDS system, separate programs were written to supply reports. It is not possible to record responses from response devices other than the computer keyboard in MicroCAT applications. Response times to individual items are measured with an accuracy of $55 \mathrm{msec}$.

An advantage of MicroCAT is its powerful tool for test and item evaluation, which can be used for test construction. MicroCAT applications can easily be integrated into MINDS.

\section{Other Programs}

Other options with MINDS include programs that test the additional hardware, an ASCII-file editor, the possibility of entering certain DOS commands (e.g., to list data files, to copy files, and to list the directory), and programs that process raw data collected previously.

At present, data are written to individual files. Future work will be directed toward the organization of data into a common database.

\section{The Organization of MINDS}

MINDS runs under MS-DOS. A hard disk is recommended. Most of the programs (except for the questionnaire administration programs) are written in Turbo Pascal.

The administration of tests and processing of data is accomplished by writing and running batch files. The organization of the software is shown schematically in Figure 2 . The main batch file calls the program MINDSHLL.

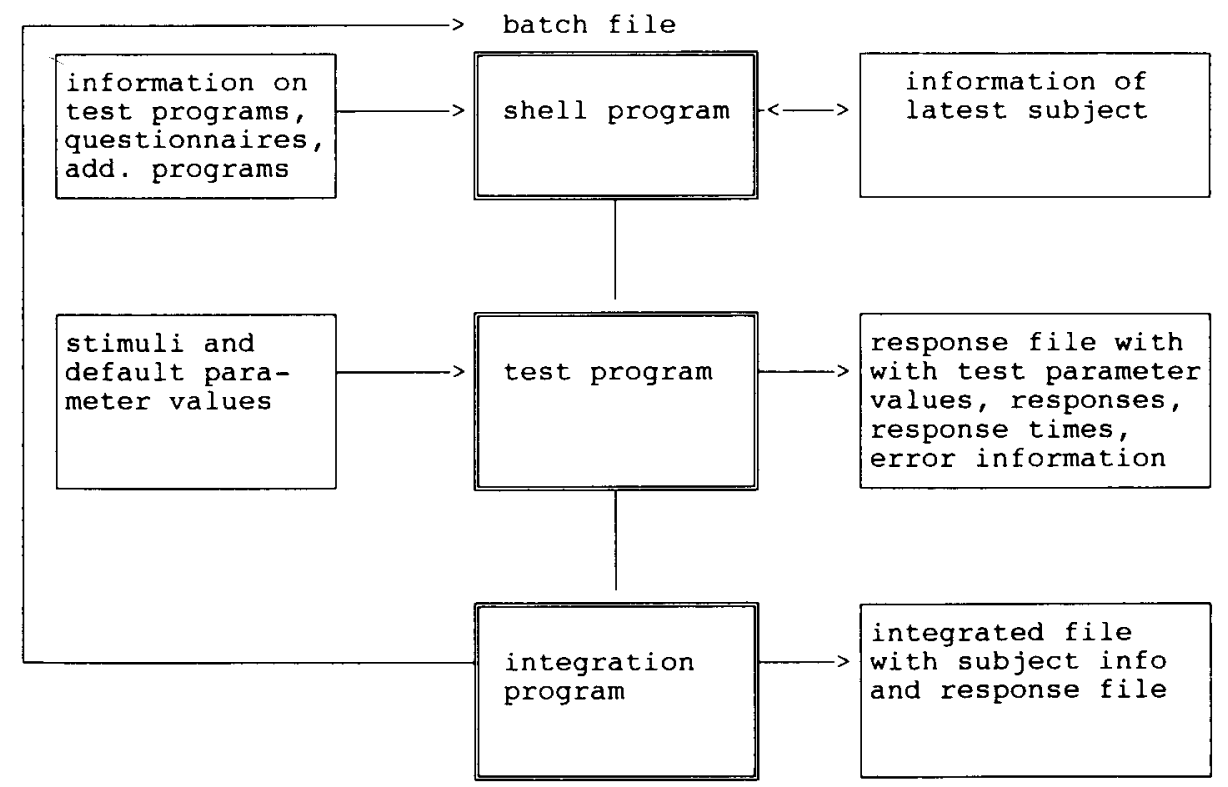

Figure 2. Schematic representation of the software organization of the MINDS system. 
In this program, the user may handle subject information, call a test program, or select data files for processing and report.

Subject information (e.g., name or identification code, sex, birthdate, handedness, etc.) of the latest subject is kept and updated in a text file. Information about available performance tests, questionnaires, or additional programs is read from other ASCII text files and presented in simple menus. In this manner, tests or other programs can easily be added to the system; the menus adapt themselves to the information in these files.

To run a certain test program, the startup name must be written to another batch file, which is then executed.

Most test programs read in information about test parameters and items from separate ASCII files. Data (reaction times, response button codes, and error information) are written to a file. Following the execution and normal termination of a test program, the subject's response file and the subject's information file are combined into a single file. The integration does not take place if an option other than test or questionnaire administration is chosen, or if an administration program is abnormally terminated. After selecting a data-processing program, the user may specify one or more response files for processing and send the output to the screen, the printer, a file, or an SPSS format file.

\section{An Example of the Performance Tests: Motor Planning}

The Motor Planning Test (MPT) was developed to meet the need for more sophisticated tasks in the clinic--tasks that measure certain aspects of motor behavior in an objective, quantitative way (Brand et al., 1990).

In this task, stimulus lights are presented to the subject from the six-button box. A short, aimed finger movement is required; the subject starts from a central start button. The stimulus-response relationship is as close as possible; the stimulus light and response button are physically the same. The buttons are grouped in an arc and are equidistant from the start button.

With this task, a differentiation can be made between central planning stages and more peripheral components. That is, the preparatory planning stages prior to the movement, as well as the speed of the movement itself, are measured.

The subject always presses the start button with the index finger of the preferred hand until one of the buttons is lit. Six different conditions are possible, the most important of which are the following.

Three-choice compatible condition. One of 3 buttons is lit; the subject has to press it and return to the start button as quickly as possible.

Incompatible condition. The subject has to press the button directly at the right of the one that is lit, followed by a return to the start button.

Four time intervals are measured in most conditions. The most important of these are, first, the time between the onset of the light and the release of the start button (reaction time, or initiation time-i.e., the preparatory or planning time), and second, the time between the release of the start button and the moment of pressing the target button (movement time). We found that in normal healthy subjects, reaction time varies with task complexity. Movement time is more or less invariant across conditions that increase in complexity, although this invariance is challenged as a function of age.

Eight test parameters may be manipulated by the user. They are listed in Figure 1 (in Dutch). This screen gives a short description of the parameters, the range of possible values, and the default value. They may be summarized briefly as follows.

The number of test trials in each condition (default: 14) may range from 10 to 100 . This may be preceded by $1-20$ practice trials (standard use: 6).

The response-stimulus interval may be variable or fixed (default setting is "variable"). If set to "variable," the interval changes semirandomly between two values, with a lower limit ranging between 250 and $2,500 \mathrm{msec}$ and an upper limit ranging between 500 and $5,000 \mathrm{msec}$. Otherwise, the "fixed" interval may be manipulated. Another option is the choice of which hand must be used by the subject: the preferred hand (default setting), the nonpreferred hand, or both hands alternately. Finally, any combination from the six possible conditions may be chosen, with up to eight conditions (including the possibility of repeats of a certain condition) occurring in any order in one test run. The default is set for four conditions, increasing in complexity.

In addition to the number of errors in each condition, the median reaction time and movement time of the test trials are collected for further analysis.

Since 1985, the MPT has been administered with an Apple II to neurological and psychiatric patients, as well as to normal healthy subjects. Neurological data have been collected from Parkinson's patients, dements, and closed head injury patients, and psychiatric data have been collected from depressive patients, schizophrenics, patients with anxiety disorders, and patients with obsessive compulsive disorders. The results of this work have been published elsewhere (Brand et al., 1990). In addition, the test has been used in the studies of the relationship between aging and health-risk-related factors associated with brain dysfunction (Houx, Vreeling, \& Jolles, 1991).

Our experience with this task has shown that the MPT is a powerful instrument that is sensitive to subtle changes in cognitive and motor performance. Tables of norms are being developed for each group of patients, and for different age groups. These norms will be incorporated into the data-processing program.

\section{Questionnaires and Equivalence}

Presently, five questionnaires are part of the MINDS system. All questionnaires are based on original paperand-pencil instruments. All are presented in monochrome text mode. An alternative to a certain item can be selected by typing the matching digit and then pressing the ENTER 
key for confirmation. Following the last item, the subject may choose to review previous items and revise the answers if that is desired; however, answers to previous items are not replaced. Both answers and response times to individual items are written to a file, in addition to any revised answers.

In automating existing paper-and-pencil questionnaires, equivalence is important, because diagnosticians may wish to compare the outcome with existing norms and reference tables. According to the American Psychological Association (APA, 1986) equivalence requires that the scores of two test versions be highly correlated and that they not differ significantly. Research on equivalence has revealed that the computer-based versions of many personality scales and attitude questionnaires are equivalent. A different picture emerges with respect to many (even highly reliable) ability and neuropsychological tests. In these tests, different demands on perception or motor processes may work against equivalence.

With respect to the questionnaires included in the MINDS system, equivalence studies have been carried out. This is usually done in a counterbalanced withinsubject design, in which the order of administration is manipulated. When equivalence is found, the existing norms are included in the data-processing programs; the resulting scores are referenced to these norms in the report. When equivalence is not established with respect to a certain (sub)scale, a short message (warning) is given in the report.

\section{Final Comments}

MINDS is still in development, although it is already in use at three locations in The Netherlands. A number of improvements still have to be made, the most important of which are the implementation of a common database and the establishment of norms with respect to the performance tests. This may be an improvement with respect to subject reports (e.g., inclusion of all test results from 1 subject in a single profile).

As mentioned earlier, the data from most of the performance tests have been collected in an Apple II environment. Although these tests have been converted to the PC environment with great care, the question of whether the Apple II data can be regarded as norms in the PC environment has yet to be answered.

So far, evaluation suggests that MINDS is a simple program that is easy to use for diagnosticians who have just started working with computers.

\section{REFERENCES}

American Psychological Association (1986). Guidelines for computer-based tests and interpretations. Washington, DC: Author.
Bouman, T. K., Wolters, F. J. M., \& Wolters-Hoff, G, H. (1989). Een schaal om attitudes tegenover computers te meten. Nederlands Tijdschrift voor de Psychologie, 44, 288-292.

BRAND, N. (1987). Memory, information processing and depression. Utrecht: Elinkwijk.

BrAND, N., Jolles, J. (1985). Learning and retrieval rate of words presented auditorily and visually. Joumal of General Psychology, 112, 201-210.

BRAND, N., Jolles, J. (1987). Information processing in depression and anxiety. Psychological Medicine, 17, 145-153.

BRAND, N., Jolles, J. (1988). "NEUROPSYCH": Computer assisted neuropsychological assessment. In F. J. Maarse, L. J. M. Mulder, W. P. B. Sjouw, \& A. E. Akkerman (Eds.), Computers in psychology: Methods, instrumentation and psychodiagnostics (pp. 149-156). Lisse: Swets \& Zeitlinger.

Brand, N., Jolles, J., \& Gispen-de Wied, C. (in press). Recall and recognition memory deficits in depression. Joumal of Affective Disorders.

Brand, N., Mol, E. (1989). Een Amerikaanse shell: MicroCAT. Psychologie en Computers, 6, 110-119.

Brand, N., Olff, M., Hulsman, R., Slagman, C. (1991). Perceptual defense: The use of digitized pictures. In M. Olff, G. Godaert, \& H. Ursin (Eds.), Quantification of human defence (pp. 293-301). Heidelberg: Springer-Verlag.

Brand, N., Wuk, A. van der, Human, R. (1990). Motor planning in neurological and psychiatric patients. In P. J. Drenth, J. A. Sergeant, \& R. J. Takens (Eds.), European perspectives in psychology (Vol. 2, pp. 321-334). Chichester, U.K.: Wiley.

Derogatis, L. R., Lipman, R. S., Covi, L. (1973). SCL-90: An outpatient psychiatric rating scale-preliminary. Psychopharmacology Bulletin, 9, 13-27.

Hamers, H., Houx, P. J., Brand, N., Jolles, J. (1992). Neuropsychological tests: Background, procedure, and hardware. Manuscript in preparation.

Houx, P. J. (1991). Cognitive aging and health-related factors. Unpublished doctoral dissertation, Rijksuniversiteit Limburg, Maastricht, The Netherlands.

Houx, P. J., Vreeling, F. W., Jolles, J. (1991). Age associated cognitive decline is related to biological life events. In $\mathrm{K}$. Iqbal, D. R. C. McLachlin, B. Winblad, \& H. M. Wisniewski (Eds.), Alzheimer's disease: Basic mechanisms, diagnosis and therapeutic strategies (pp. 353-358). Chichester, U.K.: Wiley.

Mattson, J. M., Natsoulas, T. (1962). Emotional arousal and stimulus duration as determinants of stimulus selection. Joumal of $A b$ normal \& Social Psychology, 65, 142-144.

Ploeg, M. M. VAN DER, (1982). De Zelf-Becordelings Vragenlijst (STAY-DY). Tijdschrift voor Psychiatrie, 24, 576-588.

Schreurs, P. J. G., Willege, G. Van de, Tellegen, B., BrossCHOT, J. F. (1988). Handleiding bij de Utrechtse Coping Lijst. Lisse: Swets \& Zeitlinger.

SternderG, S. (1975). Memory scanning: New findings and current controversies. Quarterly Joumal of Experimental Psychology, 27, 1-32.

Vingerhoets, A. J. J. M., JeningA, A. J., \& Menges, L. J. (1989). Het meten van Chronische en Alledaagse Stressoren: Eerste Onderzoekservaringen met de Alledaagse Problemen Lijst (APL) II. Gedrag \& Gezondheid, 17, 10-17.

Weiss, D. J., VAlE, C. D. (1987). Adaptive testing. Applied Psychology: An International Review, 36, 249-262.

West, R., Christie, M., Weinman, J. (1990). Microcompusers, psychology and medicine. Chichester, U.K.: Wiley.

WiLkinson, R. T. (1970). Methods for research on sleep deprivation and sleep function. In E. Hartmann (Ed.), Sleep and dreaming. (pp. 369-381). Boston: Little \& Brown. 